\title{
Bilateral adrenal lymphoma presenting as Addison's disease
}

\author{
A. Pagliuca' ${ }^{1}$ D.S. Gillett ${ }^{3}$, J.R. Salisbury ${ }^{2}$, R.N. Basu ${ }^{3}$ and G.J. Mufti ${ }^{1}$ \\ 'Departments of Haematological Medicine and ${ }^{2}$ Morbid Anatomy, King's College Hospital, London, and \\ Department of ${ }^{3}$ Haematology and Histopathology, Pembury Hospital, Kent, UK.
}

\begin{abstract}
Summary: We describe an unusual case of non-Hodgkin's lymphoma of the adrenals which presented as Addison's disease. Examination of tissue taken by computed tomography guided biopsy revealed a high grade B cell centroblastic lymphoma. The patient was treated with chemotherapy but died from invasive aspergillosis. Autopsy confirmed bilateral adrenal involvement by lymphoma.
\end{abstract}

\section{Introduction}

Non-Hodgkin's lymphoma has an extranodal origin in approximately $10-25 \%$ of cases. ${ }^{1}$ Adrenal involvement at the time of presentation is rare and may be difficult to establish. Surprisingly, adrenal involvement by lymphoma at post-mortem occurs in up to $35 \%$ of cases, usually associated with retroperitoneal lymph node involvement. ${ }^{2,3}$

It is generally believed that at least $90 \%$ of adrenal cortical tissue must be destroyed before the clinical features of adrenal dysfunction ensue. ${ }^{4}$ We present an unusual case of Addison's disease in whom large bilateral adrenal masses proved to be centroblastic lymphoma on biopsy.

\section{Case report}

A 59 year old man presented with a 6-month history of nausea, vomiting and lethargy associated with night sweats and weight loss. On examination he was noted to have increased palmar crease pigmentation. His blood pressure was $110 / 70 \mathrm{mmHg}$. Abdominal examination revealed two large abdominal masses which moved with respiration. Both the liver and spleen were palpable just below the costal margin.

The patient had a normocytic normochromic anaemia with a haemoglobin of $10.4 \mathrm{~g} / \mathrm{l}$. Serum sodium and potassium were normal but the urea was raised at $15.3 \mathrm{mmol} / 1$. Blood glucose was $7.1 \mathrm{mmol} / 1$. Alkaline phosphatase was raised at $336 \mathrm{IU} / 1$ with a raised bone isoenzyme, otherwise the liver function tests were normal.

Correspondence: G.J. Mufti, M.R.C.Path.

Accepted: 14 March 1989
Thyroid function was normal. A short Synacthen test (Ciba,UK) was carried out ( $250 \mu \mathrm{g}$ of tetracosactrin intramuscularly) which showed a baseline cortisol of $300 \mathrm{nmol} / 1,20$ minute cortisol of $340 \mathrm{nmol} / 1$ and a 60 minute cortisol of $340 \mathrm{nmol} / \mathrm{l}$. Corticotrophin (ACTH) was raised at $98 \mathrm{ng} / 1$ confirming Addison's disease. Adrenal autoantibodies were not assessed.

Abdominal ultrasound revealed bilateral adrenal masses with enlargement of both liver and spleen. These findings were confirmed on abdominal computed tomographic (CT) scanning (Figure la,b). There was no evidence of lymphadenopathy elsewhere. The left adrenal was biopsied under CT guidance. Histology showed complete replacement of adrenal tissue by a population of large malignant cells with rounded nuclei and multiple nucleoli (Figure 2), which precluded any histological assessment of a pre-existing autoimmune process. Immunohistochemistry showed these cells to express leucocyte common antigen (CD45) and the B cell marker MB1 (CD45R). T cell markers UCHL1 and MT1 were both negative. A diagnosis of a high grade $B$ cell centroblastic non-Hodgkin's lymphoma was made. The bone marrow aspirate and trephine were normal with no evidence of infiltration by centroblasts.

He was rehydrated and started on fludrocortisone $100 \mu \mathrm{g}$ daily with improvement in his symptoms and normalization of his renal function. Once stabilized he was started on combination chemotherapy with MACOP-B, ${ }^{5}$ which includes methotrexate, adriamycin, cyclophosphamide, vincristine, bleomycin and daily prednisolone $(50 \mathrm{mg})$ and was discharged home after the first week of therapy.

Five days after his first dose of methotrexate (700 mg) he developed severe mucositis and hypotension (BP 70/50 $\mathrm{mmHg}$ ) and was readmitted requiring intravenous fluids and hydrocortisone. Despite these

(C) The Fellowship of Postgraduate Medicine, 1989 
a

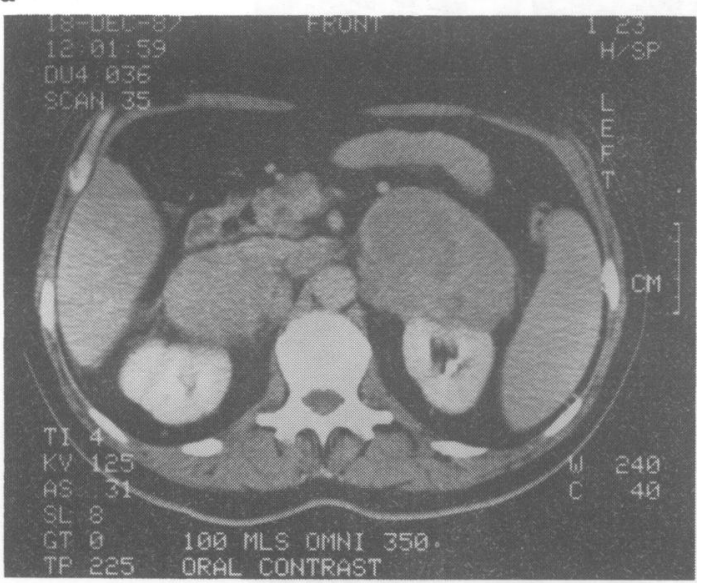

b

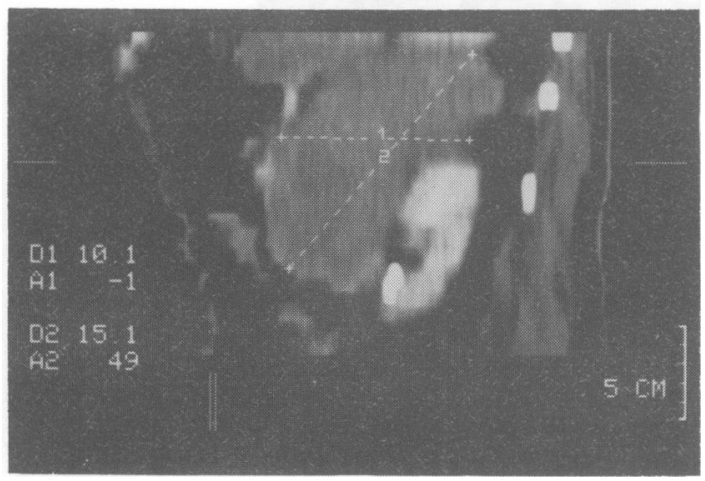

Figure 1 (a) Contrast enhanced scan at the mid renal level. Large masses are seen lying anterior to both kidneys. Further scans and saggital reconstruction (b) confirmed that the masses arose from the adrenals.

measures his clinical condition deteriorated and he developed a profound pancytopenia with bone mar row aspiration confirming a drug-induced aplasia. Ten days after admission he developed invasive aspergillosis of the lungs from which he succumbed.

Post-mortem examination revealed markedly enlarged and necrotic adrenals which were completely replaced by lymphoma. Liver and spleen were both enlarged but there was no intra-abdominal lymphadenopathy. Both kidneys showed patchy mononuclear cell infiltrates but no lymphomatous infiltration. The lungs showed haemorrhagic infarction with thrombosis of pulmonary vessels and extensive infiltration by septate, dichotomously branching fungal hyphae with the appearance of Aspergillus.

\section{Discussion}

Bilateral adrenal masses are rare and in the absence of clinical manifestations it is often difficult to distinguish primary adrenal neoplasms from infiltration by metastases and reticuloses. Assessment by conventional radiological methods may be difficult; however, computed tomography ${ }^{6}$ and magnetic resonance imaging ${ }^{7}$ have proved to be useful non-invasive techniques which may help to characterize the cause of adrenal enlargement.

Enlargement of both liver and spleen in our case was suggestive of non-Hodgkin's lymphoma and this was confirmed by CT guided needle biopsy of the left adrenal mass. Surprisingly there was no enlargement of lymph nodes elsewhere.

Unlike the thyroid gland, involvement of the adrenals as the presenting manifestation of lymphoma is unusual with only five cases ${ }^{8-12}$ reported in the literature, of which only one had bilateral involvement. ${ }^{12}$ Furthermore, presentation of lymphoma with the clinical and biochemical features of Addison's disease as illustrated by our case has only been reported once. ${ }^{13}$ In the absence of any evidence of non-Hodgkin's lymphoma in other lymph glands we postulate that the primary site of lymphoma in this case was the adrenal gland. In common with other endocrine lymphomas one might speculate that transformation may have occurred secondary to a preexisting autoimmune state ${ }^{14}$ however, we were not able to prove this.

In conclusion, despite the rarity of this presentation primary adrenal lymphoma should be excluded in the evaluation of adrenal masses presenting with Addison's disease. 


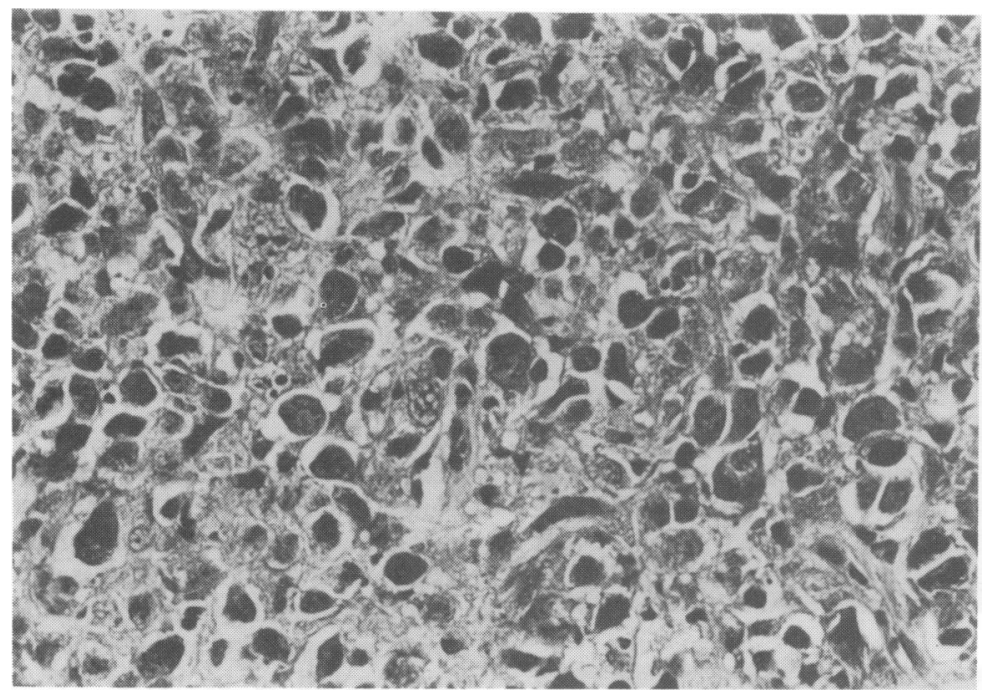

Figure 2 Needle biopsy specimen of left adrenal showing large malignant cells with rounded nuclei and prominent nucleoli (H \& $\mathrm{E} \times 288)$.

\section{References}

1. Rudders, R.A., Ross, M.E. \& DeLellis, R.A. Primary extranodal lymphoma. Response to treatment and factors influencing prognosis. Cancer 1978, 42: 406-416.

2. Rosenberg, S.A., Diamond, H.D., Jaslowitz, B. \& Craver, L.F. Lympho-sarcoma: a review of 1269 cases. Medicine 1961, 40: 31-84.

3. Straus, D.J., Filippa, D.A., Lieberman, P.H. et al. The non-Hodgkin's lymphomas. 1. A retrospective clinical and pathologic analysis of 499 cases diagnosed between 1958 and 1969. Cancer 1983, 51: $101-109$.

4. Symmers, W. St. C. Systemic Pathology, 2nd edition. Churchill Livingstone, London, 1978.

5. Klimo, P. \& Connors, J.M. MACOP-B chemotherapy for the treatment of diffuse large-cell lymphoma. Ann Intern Med 1985, 102: 596-602.

6. Curtis, J.A., Brennan, R.E. \& Kurtz, A.B. Evaluation of adrenal disease by computed tomography. $J$ Comput Tomogr 1980, 4: 165-168.

7. Reinig, J.W., Doppman, J.L., Dwyer, A.J. \& Frank, J. MRI of indeterminate adrenal masses. AJR 1986, 147: 493-496.
8. Foster, S.C. \& Gauvin, G. A man with a large suprarenal mass. Urol Radiol 1983, 5: 58-61.

9. Vicks, B.S., Perusek, M., Johnson, J. \& Tio, F. Primary adrenal lymphoma: CT and sonographic appearances. $J$ Clin Ultrasound 1987, 15: 135-139.

10. Jafri, S.Z.H., Francis, I.R., Glazer, G.M. et al. CT detection of adrenal lymphoma.J Comput Assist Tomogr 1983, 7: 254-256.

11. Cunningham, J.J. Ultrasonic findings in 'primary' lymphoma of the adrenal area. J Ultrasound Med 1983, 2: 467-469.

12. Aron, E., Jobard, P., Groussin, P. \& Jankowski, J.M. Lymphosarcome bilatéral et primitif des glands surrénales. Sem Hôp Paris 1971, 47: 3067-3071.

13. Sparagana, M. Addison's disease due to reticulum cell sarcoma apparently confined to the adrenals. $\mathrm{J} \mathrm{Am}$ Geriatr Soc 1970, 18: 550-554.

14. Hamburger, J.I., Miller, J.M. \& Kini, S.R. Lymphoma of the thyroid. Ann Intern Med 1983, 99: 685-693. 